\title{
The Role of the Striatum in Effort-Based Decision-Making in the Absence of Reward
}

\author{
Nathalie Schouppe, ${ }^{1}$ Jelle Demanet, ${ }^{1}$ Carsten N. Boehler, ${ }^{1}$ K. Richard Ridderinkhof, ${ }^{2,3}$ and Wim Notebaert ${ }^{1}$ \\ ${ }^{1}$ Department of Experimental Psychology, Ghent University, 9000 Ghent, Belgium, and ${ }^{2}$ Department of Psychology and ${ }^{3}$ Cognitive Science Center \\ Amsterdam, University of Amsterdam, 1018 XA Amsterdam, The Netherlands
}

Decision-making involves weighing costs against benefits, for instance, in terms of the effort it takes to obtain a reward of a given magnitude. This evaluation process has been linked to the dorsal anterior cingulate cortex (dACC) and the striatum, with activation in these brain structures reflecting the discounting effect of effort on reward. Here, we investigate how cognitive effort influences neural choice processes in the absence of an extrinsic reward. Using functional magnetic resonance imaging in humans, we used an effort-based decision-making task in which participants were required to choose between two options for a subsequent flanker task that differed in the amount of cognitive effort. Cognitive effort was manipulated by varying the proportion of incongruent trials associated with each choice option. Choice-locked activation in the striatum was higher when participants chose voluntarily for the more effortful alternative but displayed the opposite trend on forced-choice trials. The dACC revealed a similar, yet only trend-level significant, activation pattern. Our results imply that activation levels in the striatum reflect a cost-benefit analysis, in which a balance is made between effort discounting and the intrinsic motivation to choose a cognitively challenging task. Moreover, our findings indicate that it matters whether this challenge is voluntarily chosen or externally imposed. As such, the present findings contrast with classical findings on effort discounting that found reductions in striatum activation for higher effort by finding enhancements of the same neural circuits when a cognitively challenging task is voluntarily selected and does not entail the danger of losing reward.

\section{Introduction}

Choices are guided by cost-benefit analyses, taking into account expectations of reward and effort investment. This effort investment is mostly experienced as aversive (Botvinick, 2007). For instance, it is a general observation that, when rewards are held constant, animals as well as humans tend to prefer the least effortful choice alternative (law of least work; Hull, 1943; Kool et al., 2010). Also, rewards can acquire a lower net value when more effort is required to obtain them (i.e., effort discounting; Prévost et al., 2010; Westbrook et al., 2013), indicating that effort is costly (see also Kool and Botvinick, 2012).

Extant studies have assigned a key role to the striatum and the dorsal anterior cingulate cortex (dACC) in the computation of effort-related costs. For instance, animal studies have indicated that lesions, or dopamine depletion, in these neural structures impair effort-based decision-making, leading rats to choose the low effort-low reward option (for review, see Salamone et al., 2012). Moreover, functional magnetic resonance imaging (fMRI) studies with humans have shown that activation in the ventral striatum (VS) and dACC reflect both anticipated rewards and effort, with activation to expected rewards being discounted

Received March 20, 2013; revised Dec. 13, 2013; accepted Dec. 29, 2013.

Author contributions: N.S., J.D., C.N.B., K.R.R., and W.N. designed research; N.S. and J.D. performed research; N.S., J.D., and C.N.B. analyzed data; N.S., J.D., C.N.B., K.R.R., and W.N. wrote the paper.

This research was supported by Research Foundation-Flanders Grant $3 F 011209$.

The authors declare no competing financial interests.

Correspondence should be addressed to Nathalie Schouppe, Department of Experimental Psychology, Henri Dunantlaan 2, B-9000 Ghent, Belgium. E-mail: Nathalie.Schouppe@Ugent.be.

DOI:10.1523/JNEUROSCI.1214-13.2014

Copyright $\odot 2014$ the authors $\quad 0270-6474 / 14 / 342148-07 \$ 15.00 / 0$ by the amount of effort to be invested (Croxson et al., 2009; see also Botvinick et al., 2009; Kurniawan et al., 2013).

However, to date, only two fMRI studies have investigated effort-based choices in humans. The study by Kurniawan et al. (2010) showed higher VS activation when participants chose for an option that required less physical effort compared with an option that required more physical effort. Moreover, Prévost et al. (2010) demonstrated how activation in the dACC and anterior insula at the moment of choice represented the subjective devaluation of a reward by the need to exert effort to obtain it. Importantly, the level of reward delivered after each choice was also manipulated (i.e., effort discounting) in these studies, such that pure effort-related choices unbiased by reward expectation could not be investigated. Moreover, both studies focused on choicerelated processes based on physical effort, leaving it an open question whether cognitive effort-based choices also rely on similar neural substrates (Schmidt et al., 2012).

To investigate cognitive effort-related choice, unrelated to reward expectations, we developed an effort-based decisionmaking paradigm in which participants were asked to choose between a low and high cognitively demanding option in the absence of extrinsic reward. Moreover, we directly compared a choice versus a no-choice condition, so that pure voluntary choice-related processes can be dissociated from cue-related and preparatory processes (Croxson et al., 2009). Cognitive effort was manipulated in terms of the proportion of incongruent trials in a response interference task (cf. Schmidt et al., 2012), with the level of cognitive effort being higher for the option with more incongruent trials. 


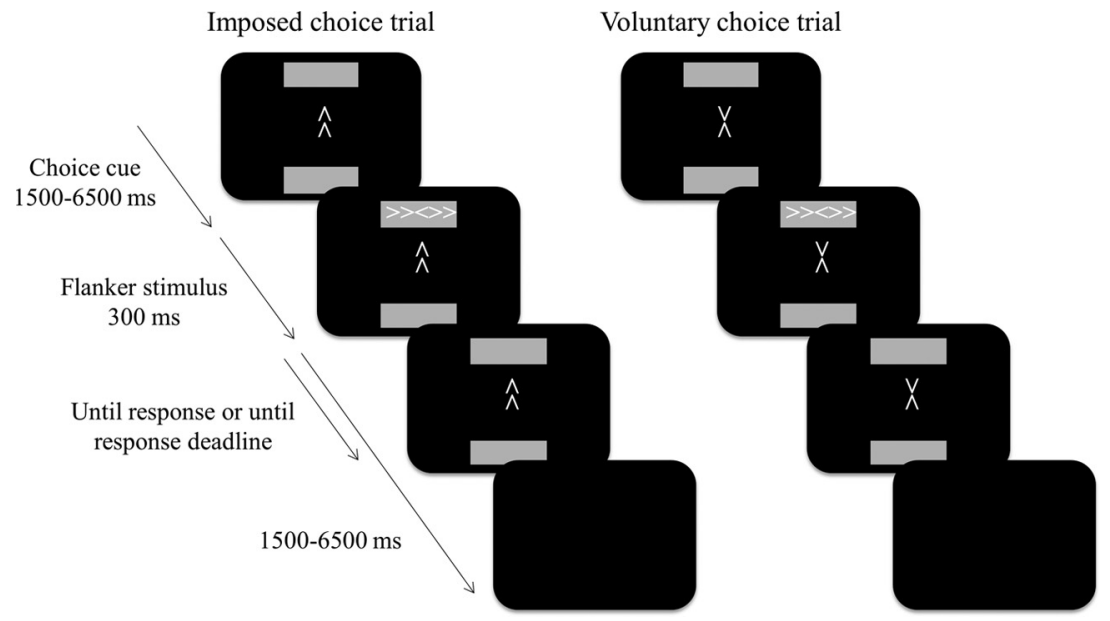

Figure 1. Sequence of events in case of a correct response on both the choice cue and flanker stimulus. A trial started with the presentation of a choice cue, imposed (left) or voluntary (right), and two gray squares denoting the two possible locations. Participants had to respond to the choice cue in a $1500 \mathrm{~ms}$ interval. From the presentation of the choice cue, a variable time interval $(1500-6500 \mathrm{~ms})$ started, after which the flanker stimulus was presented on one of the two locations. The flanker stimulus remained on the screen for $300 \mathrm{~ms}$. The screen turned black after the response on the flanker stimulus or when the response deadline (1000 ms) was exceeded. From the presentation of the flanker stimulus, a variable time interval ( $1500-6500 \mathrm{~ms})$ started until the beginning of the next trial.

\section{Materials and Methods \\ Participants}

Twenty-five right-handed students from Ghent University (range, 19-25 years of age; 22 females) participated in this study. Three participants had to be excluded based on technical issues (see below), resulting in a final sample of 22 participants (range, 19-25 years of age; 20 females). All participants had normal or corrected-to-normal vision, and none reported a history of neurological or psychiatric disorder or any other past major medical issue. The participants provided written informed consent and were paid $€ 35$ for their participation. The study procedures were approved by the local ethics committee and complied with the relevant laws and institutional guidelines.

\section{Stimuli and procedure}

Trials consisted of a cue-target sequence, wherein the cues either dictated the choice of one of two possible target locations or indicated that the location could be freely chosen. After selecting the target location, participants had to respond to the flanker stimulus by indicating the direction of the central arrow. Critically, the two locations differed in conflict likelihood, in that one location was associated with $80 \%$ congruent and $20 \%$ incongruent flanker stimuli, whereas the other location was associated with $20 \%$ congruent and $80 \%$ incongruent flanker stimuli. Based on the type of choice cue, participants could voluntarily choose the location or were forced to choose one of the two locations. In the instructions, it was stressed that, on voluntary choices, participants should choose freely but as randomly (and unpredictable) as possible. This random instruction was implemented so as to ensure that enough events per condition could be sampled, which is important for the data analysis. Free and voluntary choice cues were randomly presented, with the restriction that half of the trials were imposed choice cues and the other half were voluntary choice cues. Moreover, the presentation of the upward and downward imposed choice cues was random, with $50 \%$ of the imposed choice cues pointing upward and $50 \%$ pointing downward.

Each trial (Fig. 1) started with a centrally presented choice cue and the presentation of two gray squares denoting the two possible locations, positioned $\sim 3.5^{\circ}$ above and below fixation. The choice cue and the two gray squares remained on the screen until the end of the trial. The choice cue could either indicate a voluntary choice (i.e., participants could freely choose the location) or an imposed choice (i.e., participants were instructed to choose the upper or lower location). There was a maximum response time window of $1500 \mathrm{~ms}$. When participants responded incorrectly to the choice cue or did not respond in time, the screen turned black and a jittered intertrial interval started. From the presentation of the choice cue, there was a variable time interval until the presentation of the flanker stimulus, or, in case there was an incorrect choice response, until the presentation of the black screen. The flanker stimulus disappeared from the screen after $300 \mathrm{~ms}$, and there was a $1000 \mathrm{~ms}$ deadline to respond. When this time window of $1000 \mathrm{~ms}$ was exceeded, the screen turned black. The presentation of the flanker stimulus was followed by a jittered time interval until the beginning of the next trial. The jittered time intervals followed a distribution with pseudo-logarithmic density (range, 1500-6500 ms, in steps of $250 \mathrm{~ms}$; mean jitter, $3416.7 \mathrm{~ms}$ ).

Participants completed four blocks of 120 trials in the scanner, with self-paced breaks between blocks. Before scanning, participants completed a practice block of 150 trials. This practice block only contained imposed choice cues and was used to familiarize participants with the trial procedure. Furthermore, after scanning, participants had to complete an additional block of 100 trials. This post-scanning block only contained voluntary choices. Participants were instructed to freely choose between the locations. They were told that, if they had developed a preference for one of the two locations during the course of the experiment, they were now free to choose this location as often as they liked. This post-experiment preference task was used to validate the conclusion that participants in general show a choice bias toward the lowconflict location.

Location-to-proportion conflict and hand-to-task mappings were manipulated between subjects. Because of the exclusion of participants, however, the final sample was not perfectly counterbalanced in terms of these two variables. Twelve participants were instructed to use their right hand to indicate the choice and their left hand to perform the flanker task. Ten participants used their left hand to indicate the choice and their right hand to respond to the flanker stimuli. For half of the participants, the low-conflict location was the upper part of the screen and the highconflict location the lower part of the screen. For the other half of the participants, this assignment of proportion conflict to location was reversed. The hand-task and location-proportion conflict mappings remained stable across training, scanning, and post-scanning blocks for a given participant. Stimulus presentation and response registration was done using Tscope software (Stevens et al., 2006).

\section{fMRI data acquisition}

Images were collected with a 3 T Magnetom Trio MRI scanner system (Siemens Medical Systems) using a 32-channel radiofrequency head coil. Subjects were instructed to move their heads as little as possible throughout the entire scanning session. First, anatomical images were acquired using a T1-weighted 3D MPRAGE sequence to enable coregistration, normalization, and localization of areas of interest (TR, $1550 \mathrm{~ms}$; TE, $2.39 \mathrm{~ms}$; TI, $900 \mathrm{~ms}$; acquisition matrix, $256 \times 256$; FOV, $220 \mathrm{~mm}$; flip angle, $9^{\circ}$; voxel size, $0.86 \times 0.86 \times 0.9 \mathrm{~mm}$ ). During the task, whole-brain functional images were collected using a T2*-weighted EPI sequence, sensitive to BOLD contrast (TR, 2000; TE, $30 \mathrm{~ms}$; acquisition matrix, $64 \times 64$; FOV, $192 \mathrm{~mm}$; flip angle, $80^{\circ}$; voxel size, $3 \times 3 \times 3 \mathrm{~mm}$; no interslice gap; 33 axial slices). A varying number of images (range, 406494) was acquired per run.

\section{fMRI data preprocessing}

Data processing and analyses were performed using MATLAB and the SPM8 software (Wellcome Department of Cognitive Neurology, London, UK). The ArtRepair toolbox for SPM (http://www.fil.ion.ucl.ac. $\mathrm{uk} / \mathrm{spm} / \mathrm{ext} /$ \#ArtRepair) was used to detect outlier volumes concerning global intensity or large scan-to-scan movement (Mazaika et al., 2007). 
The data of three participants were unusable with ArtRepair identifying $>75 \%$ of scans as outliers. Therefore, these three participants were excluded from all additional analyses.

The first four scans of all EPI series were excluded from the analysis to allow for steady-state magnetization. Anatomical images were spatially normalized to the SPM T1-template image and resliced to a voxel size of $1 \times 1 \times 1 \mathrm{~mm}$. All functional EPIs were slice-time corrected and realigned to the first acquired EPI. Next, EPIs were spatially normalized based on the T1-derived normalization parameters and smoothed with an isotropic full-width half-maximum Gaussian kernel of $8 \mathrm{~mm}$. A highpass filter of $128 \mathrm{~s}$ was applied.

\section{fMRI data analyses}

Whole-brain analysis. A standard two-stage procedure was used for statistical analysis. In the first stage, BOLD responses were modeled by delta functions at stimulus onset, which were then convolved with a standard hemodynamic response function, along with temporal and dispersion derivatives (GLM; Friston et al., 1995). The model included four regressors denoting the four conditions during selection (voluntary low-conflict choice, voluntary high-conflict choice, imposed low-conflict choice, and imposed high-conflict choice). Moreover, four regressors for the execution of the flanker trials (low conflict location-congruent, low conflict location-incongruent, high conflict location-congruent, and high conflict location-incongruent) were included, as well as six movement parameters derived from the realignment procedure. The first trial of each block, erroneous trials, and trials after errors were pooled together and modeled as separate regressors of no interest. On the second level, we set up a randomeffects flexible factorial model, as implemented in SPM8, to investigate the effects of choice type (voluntary vs imposed choice), conflict location (high-conflict location vs low-conflict location choice), and their interaction in a voxelwise manner. Coordinates of significant local maxima are reported in a standard stereotaxic reference space of the Montreal Neurological Institute (MNI) system.

To control for false-positive rates, combined voxel activation intensity and cluster extent thresholds corrected for multiple comparisons were determined using $3 \mathrm{~d} C l u s t S i m$. Ten thousand Monte Carlo simulations were run taking into account the whole-brain search volume and the estimated smoothness of each axis $(x, y$, and $z)$ of the respective group SPMs. Probability estimates of a random field of noise were generated, producing a cluster of voxels of a given extent for a set of voxels passing a voxelwise $p$ value threshold of 0.005 . Given this voxelwise threshold, the simulations determined that cluster sizes of 69.3-116 voxels, depending on the specific contrast analysis, corresponded to a combined threshold of $p<0.05$ (corrected).

Region of interest analyses. Two a priori regions of interest (ROIs) were defined: the VS and the dACC. The VS ROI was manually drawn (see Fig. $4 A$ ) based on the spatially normalized T1-weighted scans averaged across individuals, with boundary MNI coordinates (posterior/anterior $y=$ 4/19; ventral/dorsal $z=-11 / 7$; right/left outer bound $x=21 /-21$ ), incorporating anteroventral parts of the caudate, the nucleus accumbens, and neighboring parts of the anteromedial putamen (Haber and Knutson, 2010). For the dACC ROI (see Fig. 4C), we used a $4 \mathrm{~mm}$ (radius) sphere around the peak (MNI) coordinates $(x=-12 ; y=28 ; z=14)$ of the dACC cluster representing effort-discounted reward value reported in the study by Croxson et al. (2009). Moreover, to further probe the nature of the whole-brain results, and more specifically the direction of the choice type $\times$ conflict location interaction, an additional ROI was defined as two $5 \mathrm{~mm}$ spheres centered around the local activity maxima in the left and right head of the caudate nucleus. Parameter estimates ( $\beta$ values) of all conditions were extracted from these ROIs using the Marsbar toolbox (Brett et al., 2002). $\beta$ values derived from the VS and dACC ROIs were entered into a 2 (choice type) $\times 2$ (conflict location) repeatedmeasures ANOVA. Note that the $\beta$ values derived from the caudate ROI were only used to illustrate the direction of the interaction effect and not for the purpose of statistical inference (Kriegeskorte et al., 2009).
Table 1. Mean RT (in milliseconds) and error rates (in percentages) for the congruent $(\mathrm{C})$ and incongruent (IC) trials of the low-conflict and high-conflict locations, displayed separately per choice type (voluntary vs imposed)

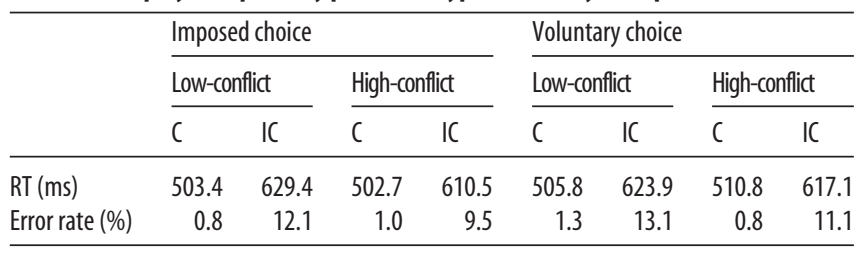

\section{Results}

Behavioral results

Manipulation check: execution of the flanker task

Before analyzing reaction times (RTs) and error rates on the flanker responses, the data were subjected to a preprocessing procedure. The first trial of each block, trials with choice errors, and trials after errors (either a choice error or flanker error) were removed. Moreover, for the RT analysis, flanker errors and outliers $( \pm 2.5 \mathrm{SD}$, calculated separately per subject, congruency, and location) were excluded, resulting in a total removal of $23 \%$. A repeated-measures ANOVA was conducted on mean RTs and error rates with choice type (imposed vs voluntary), location (high-conflict vs low-conflict), and congruency (congruent vs incongruent) as within-subjects factors. Table 1 displays mean RTs and error rates for each condition.

RTs and error rates showed a significant congruency effect, indicating slower $\left(F_{(1,21)}=183.9, p<0.001\right)$ and more error prone $\left(F_{(1,21)}=29.7, p<0.001\right)$ responses on incongruent trials compared with congruent trials. Furthermore, we found a marginally significant main effect of location on RTs $\left(F_{(1,21)}=4.0\right.$, $p=0.059)$, indicating slower responses on trials from the lowconflict location compared with trials from the high-conflict location. Moreover, an interaction between congruency and conflict location was found on RTs $\left(F_{(1,21)}=5.3, p<0.05\right)$. On error rates, a similar pattern was found, yet this was only trendlevel significant $\left(F_{(1,21)}=3.0, p=0.099\right)$. This congruency $\times$ conflict location interaction reflects the typical behavioral pattern when manipulating proportion congruency (for review, see Bugg and Crump, 2012). More specifically, a smaller congruency effect was shown for the high-conflict location compared with the low-conflict location (Table 1). All other main and interaction effects were nonsignificant (all $p$ values $>0.1$ ).

\section{Choice results}

In-scanner choices

Results showed a mean \pm SD choice rate for the low-conflict location of $48.8 \pm 10.9 \%$ (range, $23-70 \%$ ). This choice rate did not differ from chance $\left(t_{(21)}=0.53, p=0.603\right)$, indicating that participants selected the two locations equally often.

\section{Post-scanning choices}

Mean \pm SD choice rate for the low-conflict location in the postscanning task was $64.2 \pm 30 \%$ (range, $0-100 \%$ ), which differed significantly from chance $\left(t_{(21)}=2.2, p<0.05\right)$. Thus, participants displayed an overall preference for the low-conflict location. This preference was not driven by a tendency to favor one of the two physical locations. Specifically, the mean \pm SD choice rate for the upper location was $59.2 \pm 32.2 \%$, which did not differ from chance $\left(t_{(21)}=1.4=p>0.1\right)$. Furthermore, results showed a significant correlation between the choice rate for the lowconflict location in the scanner and the preference rate expressed after scanning $(r=0.605, p<0.01)$. 
Voluntary $>$ Imposed
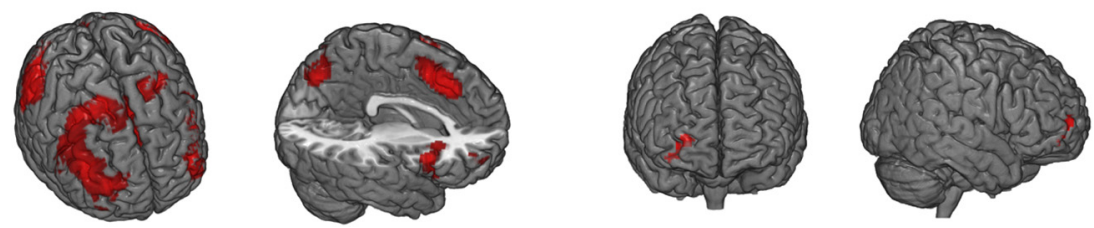

Figure 2. Activation map of the whole-brain voluntary $>$ imposed choice contrast (left) and high-conflict location $>$ lowconflict location choice contrast (right).

Table 2. Clusters revealed by the main effects of choice type and conflict location and their interaction

\begin{tabular}{|c|c|c|c|c|c|}
\hline \multirow[b]{2}{*}{ Anatomical area } & \multicolumn{3}{|c|}{ MNI coordinates } & \multirow[b]{2}{*}{ Extent } & \multirow[b]{2}{*}{$T_{\max }$} \\
\hline & $x$ & $y$ & $z$ & & \\
\hline \multicolumn{6}{|l|}{ Voluntary choice $>$ imposed choice } \\
\hline Right IPL, extending towards the left IPL & 54 & -37 & 49 & 2345 & 8.76 \\
\hline Pre-SMA, extending into the $\mathrm{RCZ}$ & 3 & 17 & 49 & 2994 & 8.72 \\
\hline Left MFG & -45 & 32 & 31 & 694 & 7.4 \\
\hline Left insula & -30 & 20 & 7 & 219 & 6.22 \\
\hline \multicolumn{6}{|l|}{ High-conflict > low-conflict choice } \\
\hline Right frontopolar cortex & 27 & 62 & 7 & 84 & 4.35 \\
\hline \multicolumn{6}{|l|}{ Choice type $\times$ conflict context } \\
\hline Right head of caudate nucleus & 18 & 20 & 4 & 93 & 4.12 \\
\hline Left head of caudate nucleus & -15 & 20 & 4 & 87 & 3.27 \\
\hline
\end{tabular}

Peak coordinates (MNl; $x, y, z)$, the number of voxels (extent), and the $t$ value of peak voxel $\left(T_{\max }\right)$ are reported for each cluster. The voxelwise (uncorrected) $p$ value threshold was 0.005 . Given this threshold, simulations using 3dClustSim determined that cluster sizes of 69.3 (high-conflict $>$ low-conflict contrast), 79.5 (interaction contrast), and 116 (voluntary $>$ imposed contrast) voxels corresponded to a combined threshold of $p<0.05$ (corrected).

\section{fMRI results}

Whole-brain analysis

Choice-related activation (voluntary $>$ imposed) was found in the presupplementary motor area (pre-SMA) extending into the rostral cingulate zone (RCZ). Also, a large cluster comprising the left and right inferior parietal lobule (IPL), as well as clusters in the insula and middle frontal gyrus (MFG), were more active during a voluntary choice compared with an imposed choice (Fig. 2, Table 2). This pattern of brain activation closely resembles other reports of choice versus no-choice contrasts (Forstmann et al., 2006; Demanet et al., 2013; Orr and Banich, 2014). Furthermore, the high-conflict $>$ low-conflict location contrast during choice showed a small activation cluster in the frontopolar cortex (Fig. 2, Table 2). Importantly, a choice type $\times$ conflict location interaction contrast revealed significant activations in the left and right head of the caudate nucleus (Fig. 3, Table 2). As can be derived from Figure $3 B$, this interaction indicated that, for voluntary choice trials, higher activation in the caudate head was found during a high-conflict choice compared with a lowconflict choice. For imposed choice trials, this activation pattern reversed.

\section{ROI analyses}

In a next step, we focused our analyses on the VS and dACC as two a priori defined ROIs, given previous reports suggesting an involvement of both regions in effort-based choice.

$V S$. A significant main effect of choice type was found $\left(F_{(1,21)}\right.$ $=6.8, p<0.05)$, as well as an interaction between choice type and conflict location $\left(F_{(1,21)}=5.5, p<0.05\right)$. This interaction is visualized in Figure $4 B$, showing a trend-level significant higher activation in the VS for a voluntary high-conflict choice compared with a voluntary low-conflict choice $\left(t_{(21)}=1.9\right.$, $p=0.073)$. The difference in activation between an imposed

\section{Follow-up analysis}

One could argue that our results were biased by an unbalanced choice contrast. More precisely, the behavioral choice pattern indicates that participants choose the two locations equally often, as instructed. However, closer examination suggests that there was variability in these choice results, with some participants choosing a given location more frequently (range of mean voluntary choice proportions for the low-conflict location, 23-70\%). As such, for some participants, parameter estimates of the lowconflict condition were calculated based on fewer trials than the estimates of the high-conflict condition and vice versa for other participants. Thus, there was within-subject variability in the estimation of the effect, which could potentially violate the assumptions underlying the fMRI group-level analysis (Chen et al., 2012). We conducted a confirmation analysis in which we equated the number of trials per run in each condition, by identifying the condition with the least number of trials and randomly excluding trials in the other three conditions until the minimum was reached. This analysis yielded qualitatively the same results (on both a whole-brain and ROI level), thereby excluding this potential alternative explanation.

\section{Discussion}

The aim of the present study was to examine the neural correlates of effort-based decision-making in the absence of a reward manipulation. We used a paradigm in which participants were asked to choose between two options that differed in conflict likelihood (and hence cognitive effort). The behavioral data confirmed that our paradigm was successful in eliciting different levels of cognitive effort by placing higher control demands, as indexed by a smaller congruency effect, in the high-conflict location compared with the low-conflict location. Furthermore, participants could either voluntarily select one of the two options or were externally guided to choose one of the options. In the direct comparison between voluntary and imposed choices, we found stronger activation for voluntary choices in a frontoparietal network, including activations in pre-SMA, RCZ, insula, MFG, and IPL. Moreover, a small cluster in the frontopolar cortex revealed higher activation during high-conflict versus low-conflict choices (regardless of choice type). Importantly, activation in the striatum (i.e., caudate head and VS) represented effort-related choices. More precisely, when choosing voluntarily, participants displayed higher activation in the striatum during a high-conflict choice compared with a low-conflict choice. This pattern represents the choice process rather than cue-related processes, given that the results reversed when participants were forced to choose. Finally, as shown by an additional analysis, we could show that unequal trial numbers did not drive our main findings.

\section{The voluntary selection of options}

RCZ activation has been shown previously for the voluntary selection of actions (Mueller et al., 2007), response sets (Walton et 


\section{A}

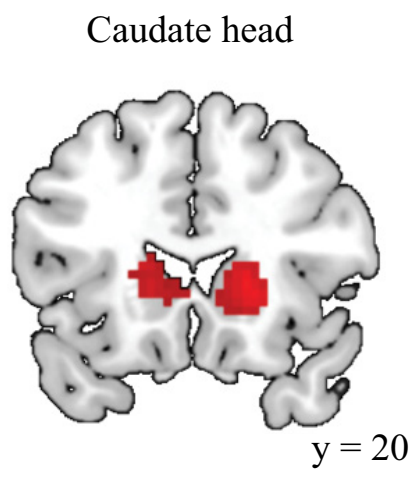

B

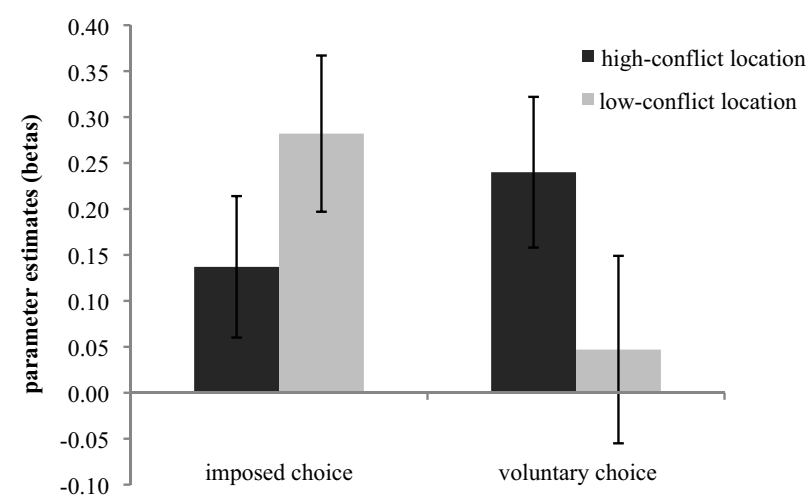

Figure 3. A, Activation map of the whole-brain interaction contrast (choice type $\times$ conflict location) during the moment of choice. $\boldsymbol{B}$, Mean $\beta$ estimates for each conflict location condition (high-conflict vs low-conflict), separately for imposed choice trials and voluntary choice trials in the head of caudate nucleus. Error bars represent \pm 1 SEM.

A

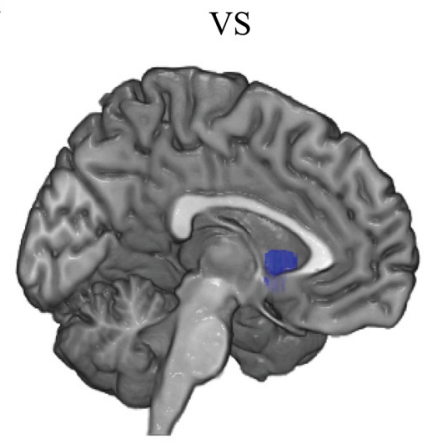

C

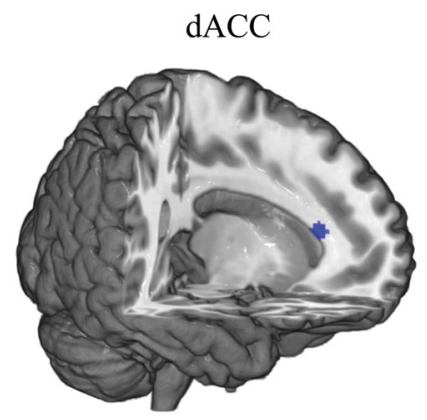

B

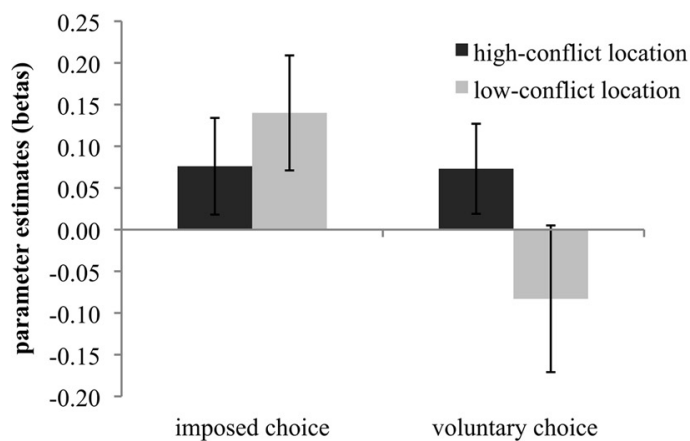

D

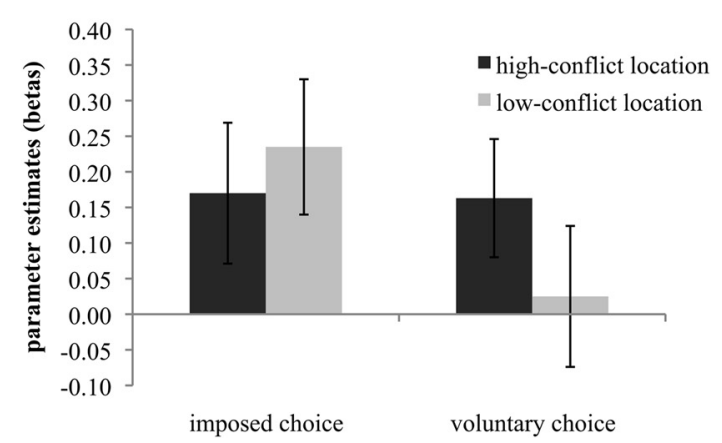

Figure 4. $A, C$, Anatomical ROls for the VS and the dACC. B, D, Mean $\beta$ estimates for each conflict location condition (high-conflict vs low-conflict), separately for imposed choice trials and voluntary choice trials in the VS and the dACC, respectively. Error bars represent \pm 1 SEM.

al., 2004), and tasks (Forstmann et al., 2006; Demanet et al., 2013), suggesting a crucial role for RCZ in internally generated choices. Corroborating these findings, our voluntary versus imposed contrast showed activation in the pre-SMA and RCZ, with the former being related to the "when" component and the latter to the "what" component of voluntary selection (Mueller et al., 2007; Krieghoff et al., 2009). The exact role of the RCZ in voluntary selection is still debated. It has been argued that the RCZ is involved in the selection of options and evaluation of the consequences of this choice (Walton et al., 2004). However, there is also an extensive literature on the role of the RCZ in conflict monitoring (for review, see Ridderinkhof et al., 2004). One might argue that, because of the random choice instruction, partici- pants in our study experienced response conflict at the moment of choice, explaining the RCZ activation in terms of conflict monitoring instead of truly reflecting a selection process between different options (for a similar argument, see Mueller et al., 2007; but see Demanet et al., 2013).

Our results also showed frontopolar activation when selecting (either in a voluntary or imposed manner) a high-conflict option compared with a low-conflict option. It is plausible that this frontopolar activation represents the relative uncertainty between the different choice options (Yoshida and Ishii, 2006; Badre et al., 2012). Alternatively, the frontopolar cortex has also been involved in "cognitive branching," a process enabling a task to be postponed until completion of another task (Koechlin and Hya- 
fil, 2007). It is likely that participants already prepared the task set of the flanker task while making a choice. Presumably, preparatory processes are more strongly engaged when anticipating high conflict, resulting in higher activation in the frontopolar cortex than when anticipating low conflict.

\section{The role of the striatum and AACC in effort discounting in the absence of extrinsic reward}

The main structure that reflected participants' voluntary choice for the low- versus high-conflict location was the striatum, which past research has traditionally labeled the reward center of the brain (Haber and Knutson, 2010). Although recent research suggests that a choice in itself is intrinsically rewarding, going along with higher activation in the caudate in a choice condition compared with a no-choice condition (Leotti and Delgado, 2011), the present data paint a more complex picture. Specifically, our data displayed an interaction between choice type and conflict location. Therein, the dominating effect was stronger striatum activation for high-conflict choices, which however was exclusive to voluntary choices, with imposed choices displaying the opposite trend. This is counter to a simple reward-inspired notion of choice-related striatum function, which would assign a rewarding quality to being allowed, as well as being imposed to choose your preferred option, because participants on average displayed a preference for the low-conflict context when allowed to choose freely in the post-scanning choice task.

Rather, our findings dovetail with studies that have reported increased activation in the VS and associated striatal structures during performance of more difficult trials in the absence of a reward manipulation, suggesting that correctly responding to difficult trials can generate an intrinsic reward signal (Lutz et al., 2012; Satterthwaite et al., 2012) and that this quality can even be relevant in an anticipatory context before successful task performance. Given that this activation pattern in the striatum was not observed in imposed choices, the activation during voluntary choices likely reflects the rewarding aspect of the choice itself and not the prospect of reward related to the upcoming trial. Our results suggest that activation in the striatum tracks the decision process in which effort-related costs are weighed against the intrinsic motivation of choosing for a more difficult task.

However, it should be noted that the intimate link between the striatum and reward processing has been put into question recently. Specifically, a more general view on striatal functioning is emerging, associating the striatum with saliency and behavioral activation (Zink et al., 2004; Salamone et al., 2005; Boehler et al., 2011; Guitart-Masip et al., 2011; for a review on the role of striatal dopamine, see Salamone and Correa, 2012). For instance, Zink et al. (2004) showed increased outcome-related activation in the nucleus accumbens and caudate when monetary rewards were delivered contingent on subjects' performance (i.e., salient) compared with passive reward delivery, unrelated to subjects' task performance (i.e., nonsalient), concluding that the role of the striatum in reward processing critically depends on these additional factors (Zink et al., 2003, 2006). Accordingly, a voluntary high-conflict choice is probably the most salient, arousing event. Thus, it is possible to explain the increased activation for this condition in terms of saliency, instead of reward or preference. However, at the same time, it is important to note that such an account (as well as one based on task preparation; Boehler et al., 2011; Krebs et al., 2012) has difficulties accounting for the flip during imposed choices, in that effortful trials should be more salient and require more preparation even if the choice was imposed. Still, given the diverse functions of the striatum, it is quite possible that such processes have at least contributed to the present results. In addition, there might be slight differences in the specific neural substrates; although the head of the caudate (as identified by a voxelwise analysis) and the VS (based on an a priori ROI) displayed qualitatively very similar results related to choice, one might surmise that they are differentially contributing to additional related functions (Arsalidou et al., 2013).

We did not find direct evidence for dACC modulation in our whole-brain analysis, and also the ROI analysis specifically targeting the dACC only revealed a trend-level effect. This may seem surprising given previous studies that reported larger ACC activation with increasing effort (Botvinick et al., 2009; Croxson et al., 2009). Although the studies by Croxson et al. and Botvinick et al. did not involve choices, their tasks did require the computation of costs and benefits, which underlie effort-based decisionmaking. Based on this, we could predict similar activation patterns. Importantly however, the choice aspect was lacking in these studies, such that a direct comparison of the results in not warranted. It should be noted that the study by Kurniawan et al. (2010), which did involve (physical) effort-based choices, also did not find ACC activation when comparing a choice for a high- versus low-effort option (but see Prévost et al., 2010). Although caution is needed when interpreting the trend-level significant dACC pattern, it is important to emphasize the similarity with the activation found in the caudate head and VS. Thus, it seems that these three regions act in concert during effort-based decision-making.

\section{Conclusion}

In summary, the central goal of this study was to elucidate the neural correlates of cognitive effort-related decision processes. In the absence of extrinsic incentives, participants showed higher activation in the striatum when voluntarily selecting the highconflict option compared with the low-conflict option. This pattern was reversed in imposed choices, indicating that this result pattern reflects the choice process rather than a preparatory process related to the expected level of task demands. Our results imply a central role for the striatum in the integration and computation of intrinsic effort-related costs/benefits in decision-making.

\section{References}

Arsalidou M, Duerden EG, Taylor MJ (2013) The centre of the brain: topographical model of motor, cognitive, affective, and somatosensory functions of the basal ganglia. Human Brain Mapp 34:3031-3054. CrossRef Medline

Badre D, Doll BB, Long NM, Frank MJ (2012) Rostrolateral prefrontal cortex and individual differences in uncertainty-driven exploration. Neuron 73:595-607. CrossRef Medline

Boehler CN, Hopf JM, Krebs RM, Stoppel CM, Schoenfeld MA, Heinze HJ, Noesselt T (2011) Task-load-dependent activation of dopaminergic midbrain areas in the absence of reward. J Neurosci 31:4955-4961. CrossRef Medline

Botvinick MM (2007) Conflict monitoring and decision making: Reconciling two perspectives on anterior cingulate function. Cogn Affect Behav Neurosci 7:356-366. CrossRef Medline

Botvinick MM, Huffstetler S, McGuire JT (2009) Effort discounting in human nucleus accumbens. Cogn Affect Behav Neurosci 9:16-27. CrossRef Medline

Brett M, Anton JL, Valabregue R, Poline JB (2002) Region of interest analysis using an SPM toolbox. Presented at the Eighth International Conference on Functional Mapping of the Human Brain, Sendai, Japan, June $2-6$.

Bugg JM, Crump MJC (2012) In support of a distinction between voluntary and stimulus-driven control: a review of the literature on proportion congruent effects. Front Psychol 3:367. CrossRef Medline

Chen G, Saad ZS, Nath AR, Beauchamp MS, Cox RW (2012) FMRI group 
analysis combining effect estimates and their variances. Neuroimage 60: 747-765. CrossRef Medline

Croxson PL, Walton ME, Reilly JXO, Behrens TEJ, Rushworth MFS (2009) Effort-based cost-benefit valuation and the human brain. J Neurosci 29: 4531-4541. CrossRef Medline

Demanet J, De Baene W, Arrington CM, Brass M (2013) Biasing free choices: the role of the rostral cingulate zone in intentional control. Neuroimage 72:207-213. CrossRef Medline

Forstmann BU, Brass M, Koch I, von Cramon DY (2006) Voluntary selection of task sets revealed by functional magnetic resonance imaging. J Cogn Neurosci 18:388-398. CrossRef Medline

Friston KJ, Holmes AP, Worsley KJ, Poline JP, Frith CD, Frackowiak RSJ (1995) Statistical parametric maps in functional imaging: a general linear approach. Human Brain Mapp 2:189-210.

Guitart-Masip M, Fuentemilla L, Bach DR, Huys QJ, Dayan P, Dolan RJ, Duzel E (2011) Action dominates valence in anticipatory representations in the human striatum and dopaminergic midbrain. J Neurosci 31:7867-7875. CrossRef Medline

Haber SN, Knutson B (2010) The reward circuit: linking primate anatomy and human imaging. Neuropsychopharmacology 35:4-26. CrossRef Medline

Hull CL (1943) Principles of behavior. New York: Appleton-Century.

Koechlin E, Hyafil A (2007) Anterior prefrontal function and the limits of human decision-making. Science 318:594-598. CrossRef Medline

Kool W, Botvinick M (2012) A labor/leisure tradeoff in cognitive control. J Exp Psychol Gen. Advance online publication. Retrieved January 6, 2014. doi:10.1037/a0031048. CrossRef Medline

Kool W, McGuire JT, Rosen ZB, Botvinick MM (2010) Decision making and the avoidance of cognitive demand. J Exp Psychol Gen 139:665-682. CrossRef Medline

Krebs RM, Boehler CN, Roberts KC, Song AW, Woldorff MG (2012) The involvement of the dopaminergic midbrain and cortico-striatal-thalamic circuits in the integration of reward prospect and attentional task demands. Cereb Cortex 22:607-615. CrossRef Medline

Kriegeskorte N, Simmons WK, Bellgowan PS, Baker CI (2009) Circular analysis in systems neuroscience: the dangers of double dipping. Nat Neurosci 12:535-540. CrossRef Medline

Krieghoff V, Brass M, Prinz W, Waszak F (2009) Dissociating what and when of intentional actions. Front Hum Neurosci 3:3. CrossRef Medline

Kurniawan IT, Seymour B, Talmi D, Yoshida W, Chater N, Dolan RJ (2010) Choosing to make an effort: the role of striatum in signaling physical effort of a chosen action. J Neurophysiol 104:313-321. CrossRef Medline

Kurniawan IT, Guitart-Masip M, Dayan P, Dolan RJ (2013) Effort and valuation in the brain: the effects of anticipation and execution. J Neurosci 33:6160-6169. CrossRef Medline

Leotti LA, Delgado MR (2011) The inherent reward of choice. Psychol Sci 22:1310-1318. CrossRef Medline

Lutz K, Pedroni A, Nadig K, Luechinger R, Jäncke L (2012) The rewarding value of good motor performance in the context of monetary incentives. Neuropsychologia 50:1739-1747. CrossRef Medline

Mazaika P, Whitfield-Gabrieli S, Reiss A (2007) Artifact repair for fMRI data from high motion clinical subjects. Poster presented at the 13th Annual Meeting of the Organization for Human Brain Mapping. Chicago, IL, June 10-14.

Mueller VA, Brass M, Waszak F, Prinz W (2007) The role of the preSMA and the rostral cingulate zone in internally selected actions. Neuroimage 37: 1354-1361. CrossRef Medline

Orr JM, Banich MT (2014) The neural mechanisms underlying internally and externally guided task selection. Neuroimage 84:191-205. CrossRef Medline

Prévost C, Pessiglione M, Météreau E, Cléry-Melin ML, Dreher JC (2010) Separate valuation subsystems for delay and effort decision costs. J Neurosci 30:14080-14090. CrossRef Medline

Ridderinkhof KR, Ullsperger M, Crone EA, Nieuwenhuis S (2004) The role of the medial frontal cortex in cognitive control. Science 306:443-447. CrossRef Medline

Salamone JD, Correa M (2012) The mysterious motivational functions of mesolimbic dopamine. Neuron 76:470-485. CrossRef Medline

Salamone JD, Correa M, Mingote SM, Weber SM (2005) Beyond the reward hypothesis: alternative functions of nucleus accumbens dopamine. Curr Opin Pharmacol 5:34-41. CrossRef Medline

Salamone JD, Correa M, Nunes EJ, Randall PA, Pardo M (2012) The behavioral pharmacology of effort-related choice behavior: dopamine, adenosine and beyond. J Exp Anal Behav 97: 125-146. CrossRef Medline

Satterthwaite TD, Ruparel K, Loughead J, Elliott MA, Gerraty RT, Calkins ME, Hakonarson H, Gur RC, Gur RE, Wolf DH (2012) Being right is its own reward: load and performance related ventral striatum activation to correct responses during a working memory task in youth. Neuroimage 61:723-729. CrossRef Medline

Schmidt L, Lebreton M, Cléry-Melin ML, Daunizeau J, Pessiglione M (2012) Neural mechanisms underlying motivation of mental versus physical effort. PLoS Biol 10:e1001266. CrossRef Medline

Stevens M, Lammertyn J, Verbruggen F, Vandierendonck A (2006) Tscope: a C library for programming cognitive experiments on the MS windows platform. Behav Res Methods 38:280-286. CrossRef Medline

Walton ME, Devlin JT, Rushworth MFS (2004) Interactions between decision making and performance monitoring within prefrontal cortex. Nat Neurosci 7:1259-1265. CrossRef Medline

Westbrook A, Kester D, Braver TS (2013) What is the subjective cost of cognitive effort? Load, trait, and aging effects revealed by economic preference. PLoS One 8:e68210. CrossRef Medline

Yoshida W, Ishii S (2006) Resolution of uncertainty in prefrontal cortex. Neuron 50:781-789. CrossRef Medline

Zink CF, Pagnoni G, Martin ME, Dhamala M, Berns GS (2003) Human striatal response to salient nonrewarding stimuli. J Neurosci 23:80928097. Medline

Zink CF, Pagnoni G, Martin-Skurski ME, Chappelow JC, Berns GS (2004) Human striatal responses to monetary reward depend on saliency. Neuron 42:509-517. CrossRef Medline

Zink CF, Pagnoni G, Chappelow J, Martin-Skurski M, Berns GS (2006) Human striatal activation reflects degree of stimulus saliency. Neuroimage 29:977-983. CrossRef Medline 